\title{
Effect of noscapine, the antitussive opioid alkaloid, on bradykinin-induced smooth muscle contraction in the isolated ileum of the guinea-pig
}

\author{
M. Mahmoudian, N. Mojaverian \\ Razi Institute for Drug Research, Iran University of Medical Sciences, Tehran, Iran
}

Received: November 5, 2001

Accepted: February 22, 2002

Bradykinin $(\mathrm{BK})$ and related kinins are autocoid peptides that play integral roles in many pathophysiological processes such as cough.

In this study, the inhibitory effect of noscapine, the antitussive opioid alkaloid, on BK receptors, was tested in the guinea-pig ileum. Contractions of the isolated ileum of the guinea-pig in response to BK were inhibited by noscapine $(10-1000 \mathrm{nM})$ in a concentration-dependent manner. Concentration-response curves (CRCs) to BK were slightly shifted to the right with a concomitant decrease in the maximum effect. A pA2 value of 6.68 was calculated for noscapine. The slope of the Schild plot of the antagonism was found to be 0.56 .

Noscapine had no effect on contractions induced by $\mathrm{KCl}$, acetylcholine, histamine, 5-hydroxy tryptamine or angiotensin II.

In conclusion, noscapine has a specific antagonistic effect on BK receptors and the mode of inhibition was found to be non-competitive.

Keywords: bradykinin, noscapine, muscle contraction, guinea-pig ileum

Bradykinin (BK) and related peptides are autocoids derived from enzymatic action of kallikreins on kininogens $(3,18,19)$. BK binds to specific receptors and participates in a wide number of physiological and pathological states; such as vasodilatation, control of blood pressure, smooth muscle contraction, increased vascular

Correspondence should be addressed to

M. Mahmoudian

Razi Institute for Drug Research

Iran University of Medical Sciences

Tehran, P.O. Box 14155-6183, Iran

Fax: +98-21-8058719

E-mail: masmah99@iums.ac.ir 
permeability and several inflammatory processes $(7,10,19)$. BK also participates in angiotensin-converting enzyme (ACE) inhibitors induced cough (2).

Therapy with ACE inhibitors is associated with a high prevalence of dry, nonproductive cough $(0 \%-39 \%)(8,11)$. The most logical and popular hypothesis is that the degradation of kinins, particularly BK in the airways is inhibited (15), because ACE or kininase II has a major role in the catabolism of kinins $(20,21)$.

Noscapine is a phtalideisoquinoline alkaloid obtained from opium. It lacks analgesic, sedative and respiratory depressant properties, and it does not produce euphoria or dependence (17). The only pharmacological effect of noscapine is cough suppression, for which it has been used since the mid 50s (14). Noscapine is a safe and specific antitussive through its central and peripheral activities (4). Kamei also suggested that $\sigma$ sites might be involved in the antitussive mechanism of this drug (12).

Following the discovery of two subtypes of bradykinin receptors, B1 and B2, much effort has been concentrated on the production or detection of antagonists for these receptors (19). In this study, the inhibitory effects of noscapine on BK in the guinea-pig isolated ileum were investigated.

\section{Materials and Methods}

\section{Tissue preparation}

Guinea-pigs (200-350 g) of both sexes were lightly anesthetized with chloroform, killed by a blow on the head. The guinea-pig ileum was rapidly removed and carefully dissected free from adhering tissues. Pieces of ileum ( $20 \mathrm{~mm}$ in length) were set up in $10 \mathrm{ml}$ organ baths containing Tyrode $\left(37^{\circ} \mathrm{C}\right)$ solution. Preparations were be bobbled with carbogen $\left(95 \% \mathrm{O}_{2}, 5 \% \mathrm{CO}_{2}\right)$ under $1 \mathrm{~g}$ of load. The isotonic contractions were recorded. Preparations were allowed to equilibrate for at least $60 \mathrm{~min}$ before the experiments were started, and during this period the bath solution was changed every $15 \mathrm{~min}$. Responses to BK in all tissues were determined in the presence of captopril $(3 \mu \mathrm{M})$ to avoid degradation by the action of kininase II (5).

For the construction of concentration-response curves (CRCs) for BK, the ileum of the guinea-pig was prepared as described above. After an equilibrium period, BK was applied to the organ bath in a non-cumulative manner to obtain contractions from $0.1 \mathrm{nM}$ to $100 \mathrm{nM}$. A further resting period of $30 \mathrm{~min}$ was allowed during which the bath solution was replaced with fresh solution 4-6 times. Noscapine $(10,100$ or $1000 \mathrm{nM}$ ) was added to the organ bath 5 min before the construction of a second BK 
CRC. In order to avoid or minimize BK desensitization, in each preparation, 2-3 noncumulative CRCs were obtained. All effects of BK are expressed as \% of the maximum effect established during the first CRC.

In order to exclude unspecific inhibitory effects, noscapine was also tested against the contractile responses of acetylcholine $(1 \mu \mathrm{M})$, histamine $(10 \mu \mathrm{M})$, 5-hydroxy tryptamine $(100 \mathrm{nM})$, angiotensin II $(10 \mathrm{nM})(9)$, and $\mathrm{KCl}(80 \mathrm{mM})$. The effect of noscapine on the contractile responses of the other agonists on the guinea-pig ileum was examined in the concentration of agonist causing $75 \%$ or more of maximal contractile response.

\section{Solutions and drugs}

All solutions were prepared freshly on the day of the experiments. Acetylcholine, histamine, 5-hydroxy tryptamine, angiotensin II and bradykinin were purchased from Sigma. Noscapine was a gift from TEMAD-DP CO. (Tehran-Iran).

Tyrode solution (mM): $\mathrm{NaCl} 137 ; \mathrm{KCl} 2.7 ; \mathrm{CaCl}_{2} 1.8 ; \mathrm{MgCl}_{2} 1.0 ; \mathrm{NaHCO}_{3} 11.9$; $\mathrm{NaH}_{2} \mathrm{PO} 40.4$ and glucose 5.5.

All salts were of analytic grade and were obtained from Merck.

\section{Data analysis}

The contractile responses of $\mathrm{BK}$ in the absence or presence of noscapine are presented as the percentages of maximum contractile response established during the first CRC in one tissue. The nature of the interaction of antagonists with the receptors was checked by the Schild regression as follows: antagonist-induced shifts of CRCs to the agonist were calculated graphically at the level of the half-maximal response as the ratio (concentration-ratio, CR) of equieffective concentrations of agonist. Estimates of $\log (\mathrm{CR}-1)$ were plotted against log (antagonist concentration).

Antagonists providing plots with linear regression lines and slopes less than unity were considered to act in a non-competitive manner (1). The $\mathrm{pA}_{2}$ value as an estimate for the antagonist's affinity in this tissue were derived from the linear regression analysis.

Comparisons of effects in the presence of noscapine to values obtained before were performed by means of Student's $t$-test for paired data. Differences between groups were considered to be significant at $p<0.05$. All values presented in the tables and figures are arithmetical means with s.e.mean; where no s.e.mean is indicated in a figure, it was smaller than the symbol used. 


\section{Results}

Noscapine had no effect on high concentration $\mathrm{KCl}(80 \mathrm{mM})$ induced contractions of guinea-pig ileum.

Similarly noscapine had no antagonistic effects on acetylcholine $(1 \mu \mathrm{M}$, as previously reported by Kamikawa et al. 1991) (13), histamine (10 $\mu \mathrm{M})$, 5-hydroxy tryptamine $(100 \mathrm{nM})$, and angiotensin II (10 nM) (Table I).

Addition of $\mathrm{BK}(0.1$ to $100 \mathrm{nM})$ to the organ bath, caused a concentrationdependent contractile response (first CRC). The addition of noscapine (10, 100, $1000 \mathrm{nM}$ ) to the organ bath resulted in a concentration-dependent reduction of the contractile effects of BK, in the isolated ileum of the guinea-pig (Figs 1 and 2).

Non-cumulative CRCs to $\mathrm{BK}$ in the presence of noscapine show concomitant decrease in the maximum contractile responses, and the $\mathrm{EC}_{50}$ of $\mathrm{BK}$ in the presence of the antagonist show no significant changes. $\mathrm{A} \mathrm{pA}_{2}$ value of 6.68 was calculated. The slope of Schild plot was -0.56 (Fig. 3).

\section{Discussion}

In the guinea-pig ileum, noscapine caused a reduction of the maximum effect with no significant change in the $\mathrm{EC}_{50}$ of bradykinin. The slope of the Schild plot of this interaction was calculated and found to be -0.56 . Thus a typical non-competitive mode of interaction with the BK receptors of the guinea-pig ileum can be assumed.

Table I

Comparisons of contractile responses of some agonists in the absence (A) and presence (I) of noscapine $(1 \mu M)$ in the guinea-pig ileum

\begin{tabular}{lccc}
\hline Agonist & $\begin{array}{c}\text { A } \\
\text { Mean (SEM) }\end{array}$ & $\begin{array}{c}\text { I } \\
\text { Mean (SEM) }\end{array}$ & $t$-test \\
\hline Ach $(1 \mu \mathrm{M})$ & $75.59 \%(2.04 \%)$ & $78.89 \%(3.21 \%)$ & N.S. \\
His $(10 \mu \mathrm{M})$ & $78.30 \%(2.02 \%)$ & $77.58 \%(3.08 \%)$ & N.S. \\
5 -HT $(100 \mathrm{nM})$ & $78.82 \%(2.14 \%)$ & $77.31 \%(2.28 \%)$ & N.S. \\
A II $(10 \mathrm{nM})$ & $81.21 \%(4.07 \%)$ & $79.21 \%(4.81 \%)$ & N.S. \\
\hline
\end{tabular}

Ach: Acetylcholine, His: Histamine, 5-HT: 5-Hydroxy tryptamine, A II: Angiotensin II and N.S.: No Significant. Mean (SEM) values are shown; $n=6$. 


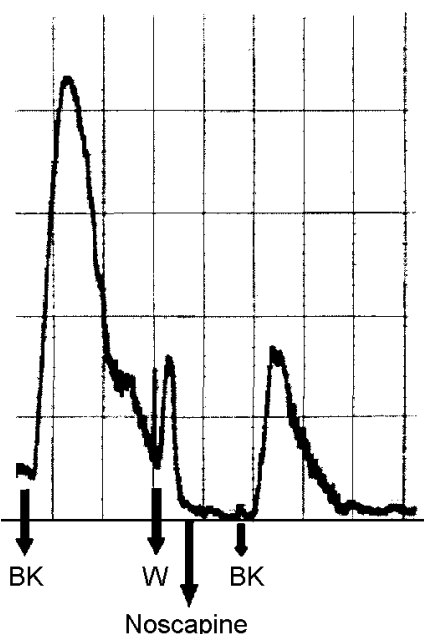

Fig. 1. Contractile responses to bradykinin $(10 \mathrm{nM})$ before and after addition of noscapine $(1 \mu \mathrm{M})$ in the guinea-pig ileum, recorded by physiograph

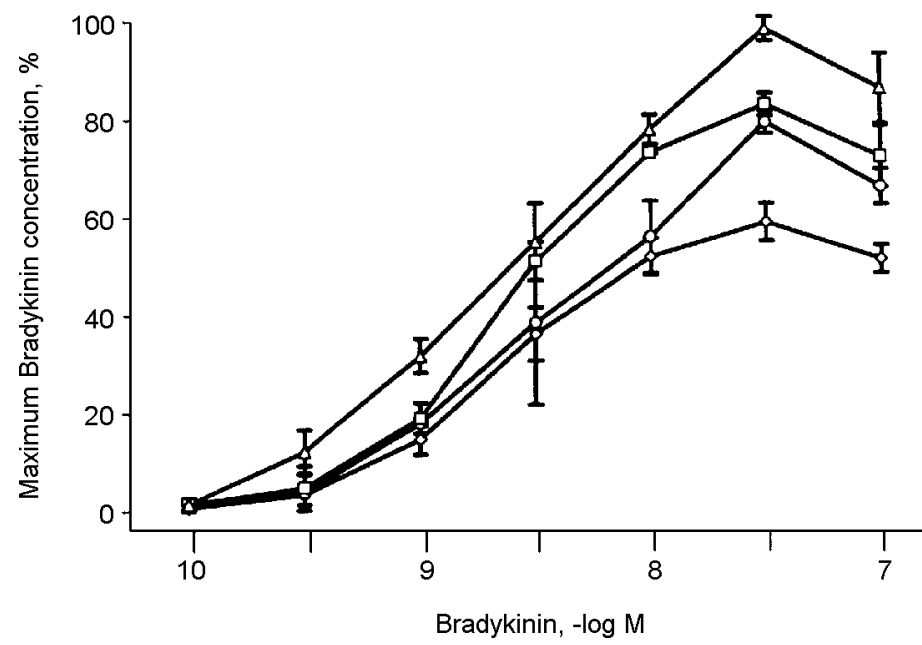

Fig. 2. Effect of noscapine and bradykinin-induved contractions of the isolated ileum of the guinea-pig Non-cumulative concentration-response curves (CRCs) to bradykinin (BK) were established under control conditions $(\Delta)$ and in the presence of noscapine $(\square: 10 \mathrm{nM}$; O: $100 \mathrm{nM} ; \diamond: 1000 \mathrm{nM})$ applied 5 min before the challenge with BK. In each individual preparation two CRCs to BK were established under control conditions and in the presence of one concentration of noscapine. Contractions are given as $\%$ of the maximum BK-induced contraction obtained at the beginning of each experiment. Mean values are shown, vertical lines indicate the standard error of the mean (SEM) $n=4-5$ 


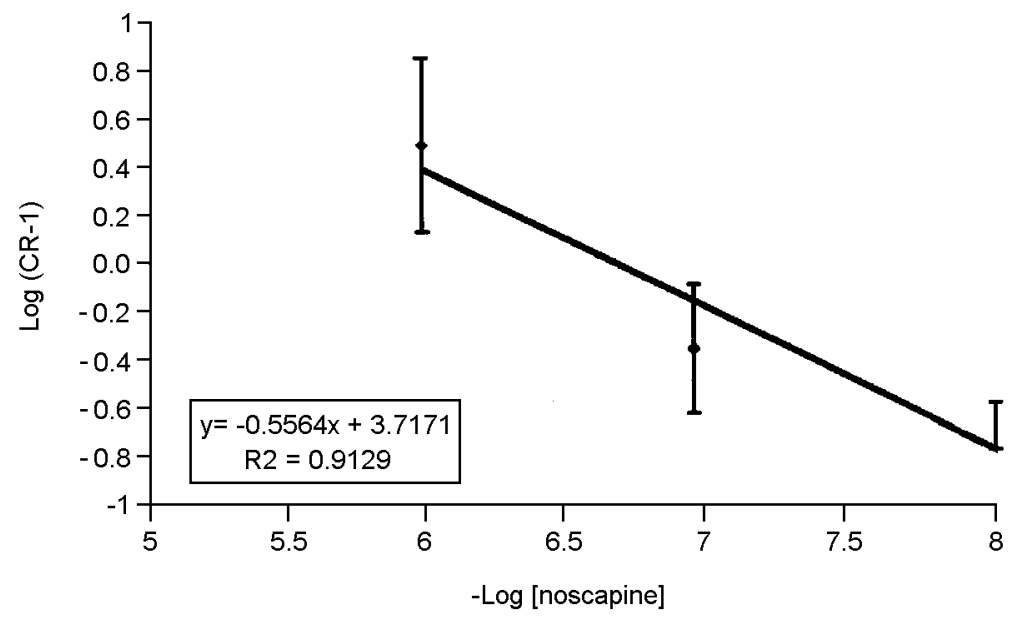

Slope $=-0.56 ; \mathrm{pA}_{2}=6.68$. Mean values are shown and vertical lines indicated s.e.mean; $n=4$.

Fig. 3. Schild plot of the antagonistic effect of noscapine on bradykinin-induced contraction in the guinea-pig ileum

Any new compound that is suggested to be a receptor antagonist must exhibit both a selective inhibition of the receptor-mediated actions of the agonist in question and a lack of effect at other receptor systems. Noscapine did not inhibit the actions of acetylcholine (similar to the result of Kamikawa et al.) (13), histamine, 5-hydroxy tryptamine or angiotensin II. Therefore, noscapine can be a specific but noncompetitive antagonist of the BK receptors.

As it has been reported in various studied, the participation of kinins in cough and BK-accumulation induced by ACE inhibitors (6) are suggested to play a major role in this adverse effect of these drugs (16). Emanueli et al. has showen that, Hoe 140, the bradykinin B2 receptor antagonist inhibits plasma extravasation increased by captopril in mice (6). Therefore, antagonists of bradykinin are of interests in various pathophysiological conditions.

In conclusion, it seems that noscapine is a specific and non-competitive antagonist of the BK receptors and this may be involved in the pharmacological effect of this drug.

\section{Acknowledgements}

Authors would like to thank Dr M.E. Zolfaghari (TEHAD-DP CO.) for a gift of noscapine and Dr D. C. Crowther (Cambridge Inst. Med. Res.) for a gift of bradykinin. 


\section{REFERENCES}

1. Arunlakshana O, Schild HO: Some quantitative uses of drug antagonism. Br. J. Pharmacol. Chemother. 14, 48-58 (1959)

2. Bertrand C, Nadel JA, Yamawaki I, Geppetti P: Role of kinins in the vascular extravasation evoked by antigen and mediated by tachy kinins in guinea pig trachea. J. Immunol. 151, 4902-4907 (1993)

3. Bhoola K, Figueroa C, Worthy K: Bioregulation of kinins: kallikreins, kininogens, and kininases. Pharmacol. Rev. 44, 1-80 (1992)

4. Bruneton J. (1995): Morphinates. In: Pharmacognosy, Phytochemistry, Medicinal Plants (translation into English of the French edition), editor Bruneton J. Third edition, Paris: Technique \& Documentation - Lavoisier Press; pp. 755-770.

5. Calixto JB: Multiple mechanisms of bradykinin-induced contraction in rat and guinea-pig smooth muscles in vitro. Eur. J. Pharmacol. 281, 279-288 (1995)

6. Emanueli C, Grady EF, Mededdu P, Figini M, Bunnett NW, Parisi D, Regoli D, Geppetti P: Acute ACE inhibition causes plasma extravasation in mice that is mediated by bradykinin and substance P. Hypertension. 31, 1299-1304 (1998)

7. Farmer SG, RM Burch: Biochemical and molecular pharmacology of kinin receptors. Annu. Rev. Pharmacol. Toxicol. 32, 511-536 (1992)

8. Franova S, Nosal'ova G, ACE-inhibitors and defence reflexes of the airways. Acta Physiol. Hung. 84, 359-366 (1997-1998)

9. Griesbacher T, Sametz W, Legat FJ, Diethart S, Hammer S, Juan H: Effects of the non-peptide B2 antagonist FR173657 on kinin-induced smooth muscle contraction and relaxation, vasoconstriction and prostaglandin release. Br. J. Pharmacol. 121, 469-476 (1997)

10. Hall JM: Bradykinin receptors: pharmacological properties and biological roles. Pharmacol. Ther. 56, 131-190 (1992)

11. Israili ZH, Hall WD: Cough and angioneuretic edema associated with angiotensin-converting enzyme inhibitor therapy. Ann. Intern. Med. 117, 234-242 (1992)

12. Kamei J: Role of opioidergic and serotonergic mechanisms in cough and antitussives. Pulmonary Pharmacology. 9, 349-356 (1996)

13. Kamikawa Y, Shimo Y: Inhibitory effect of non-narcotic antitussive drugs on cholinergically and noncholinergically mediated neurogenic contractions of guinea-pig isolated bronchial muscle. J. Pharm. Pharmacol. 43, 242-246 (1991)

14. Karlsson MO, Dahlström B, Neil A: Characterization of high affinity binding sites for the antitussive $[3 \mathrm{H}]$ noscapine in guinea pig brain tissue. Eur. J. Pharmacol. 145, 195-203 (1988)

15. Lallo UG, Barnes PJ, Chung KF: Pathophysiology, and clinical presentation of cough. J. Allergol. Clin. Immunol. 98 (5 pt 2). S 91-97 (1996)

16. Linz W, Wiemer F, Gohlke P, Unger T, Scholkens B: Contribution of kinins to the cardiovascular actions of angiotensin-converting enzyme inhibitors. Pharmacol. Rev. 47, 25-49 (1995)

17. Martindale M (1997): The Extra Pharmacopoeia. Ed: A. Wade. The Pharmaceutical Press, London p. 1250.

18. Proud D, Kaplan AP: Kinin formation: mechanism and role in inflammatory disorders. Annu. Rev. Immunol. 6, 49-83 (1988)

19. Regoli D, Barabe J: Pharmacology of bradykinin and related kinins. Pharmacol. Rev. 32, 1-46 (1980)

20. Reques BP, Noble F, Dauge V, Fournie-Szaluski M-C, Beaumont A: Neutral endopeptides 24.11: Structure, inhibition, experimental and clinical pharmacology. Pharmacol. Rev. 45, 87-146 (1993)

21. Skidgel RA, Defendini R, Erdos EG (1987): Angiotensin converting enzyme and its role in neuropeptide metabolism. In: Neuropeptides and their Properties. Ed: Turner AJ. Ellis Horwood, Chichester, UK, pp. 165-182. 